\title{
A population-based study of the risk of osteoporosis and fracture with dutasteride and finasteride
}

Tony Antoniou ${ }^{1,2,3,4^{*}}$, Erin M. Macdonald ${ }^{4}$, Zhan Yao ${ }^{4}$, Tara Gomes ${ }^{2,3,4}$, Mina Tadrous ${ }^{3,4,5}$, Joanne M.-W. Ho $0^{6,7}$, Muhammad M. Mamdani $i^{2,3,4,5,8}$, David N. Juurlink $k^{3,4,9}$ and for the Canadian Drug Safety and Effectiveness Research Network

\begin{abstract}
Background: Dutasteride is a potent inhibitor of 5-alpha reductase enzymes that reduces concentrations of dihydrotestosterone to a greater extent than finasteride. Whether this has adverse implications for bone health is unknown. We compared the risk of osteoporosis and fractures in older men treated with dutasteride or finasteride.

Methods: We conducted a population-based retrospective cohort study with high-dimensional propensity score matching of Ontario men aged 66 years or older who started treatment with dutasteride or finasteride between January 1, 2006 and December 31, 2012. The primary outcome was a diagnosis of osteoporosis within 2 years of treatment initiation. A secondary outcome was osteoporotic or fragility fractures.

Results: We studied 31,615 men treated with dutasteride and an equal number of men treated with finasteride. Dutasteride-treated patients had a lower incidence of osteoporosis than those receiving finasteride [2.2 versus 2.6 per 100 person years; hazard ratio (HR) 0.82; 95\% confidence interval (Cl) 0.72 to 0.93]. This effect was no longer statistically significant following adjustment for specialty of prescribing physician (HR 0.90; 95\% Cl 0.78 to 1.02)]. There was no differential risk of fractures with dutasteride (HR 1.04; $95 \% 0.86$ to 1.25 ).
\end{abstract}

Conclusions: Despite differential effects on 5-alpha reductase, dutasteride is not associated with an increased risk of osteoporosis or fractures in older men relative to finasteride. These findings suggest that dutasteride does not adversely affect bone health.

Keywords: 5-alpha Reductase inhibitors/adverse effects, Osteoporosis/physiopathology, Dutasteride, Finasteride

\section{Background}

Osteoporosis is an under-appreciated cause of morbidity and mortality in men $[1,2]$. Globally, one in three osteoporotic hip fractures occur in men, and a higher proportion of men than women die in the first year following a hip fracture, with mortality rates of 37.5 and $28.2 \%$, respectively [3]. Evidence suggests that androgen deficiency contributes to bone loss and fracture risk in older men [4-7]. The observation that men with osteoporosis have lower dihydrotestosterone concentrations than men with

\footnotetext{
* Correspondence: tantoniou@smh.ca

${ }^{1}$ Department of Family and Community Medicine, St. Michael's Hospital, 410

Sherbourne Street, 4th Floor, Toronto, ON M4X 1K2, Canada

${ }^{2}$ Li Ka Shing Knowledge Institute, St. Michael's Hospital, 410 Sherbourne

Street, 4th Floor, Toronto, ON M4X 1K2, Canada

Full list of author information is available at the end of the article
}

normal bone mineral density suggests an important role of this androgen in bone homeostasis $[8,9]$. Dihydrotestosterone is approximately ten times more potent than its precursor testosterone, and is the preferred ligand for androgen receptor transactivation [10]. Because 5-alpha reductases convert testosterone to dihydrotestosterone, inhibitors of these enzymes could conceivably predispose older men to osteoporosis and fractures [11].

Dutasteride and finasteride are 5-alpha reductase inhibitors that are equally effective treatments for benign prostatic hyperplasia [12]. Although considered clinically interchangeable, the two drugs differ in their spectrum of 5-alpha reductase inhibition. Finasteride is a selective inhibitor of the type 2 isoform of 5-alpha reductase, which is found predominantly in the prostate, while 
dutasteride additionally inhibits the more widespread type 1 isoform, which is the predominant 5 -alpha reductase in osteoblasts [11-13]. Because dutasteride is both a more potent and less selective inhibitor of 5 -alpha reductases, it reduces circulating serum dihydrotestosterone by 90 to $95 \%$, compared with 60 to $70 \%$ for finasteride [11, $14,15]$ In addition, dutasteride mediated-inhibition of 5alpha reductase in osteoblasts could conceivably suppress local production of dihydrotestosterone [13]. These effects may have implications for bone health, particularly among older men, because bone loss accelerates rapidly after the age of 70 years [1]. However, whether dutasteride imparts a higher risk of osteoporosis and fractures in older men receiving 5-alpha reductase inhibitors is unknown.

Several studies have examined the effects of 5 -alpha reductase inhibitors on bone mineral density. Although no significant changes in bone mineral density were observed in a one-year randomized trial of dutasteride and finasteride, the study was small and restricted to men aged 18 to 55 years [16]. Similar findings were observed in a small non-randomized study of men aged 60 to 78 years who were followed for up to two years after treatment initiation [17]. Observational studies have yielded inconsistent findings, ranging from no association between 5 -alpha reductase inhibitors and bone disease to both a higher and lower risk imparted by these drugs [18-22]. Importantly, no observational study has specifically explored whether the available 5 -alpha reductase inhibitors carry differential risks of osteoporosis or fracture in older men. This is important because benign prostatic hyperplasia is common in older men, 5-alpha reductase inhibitors are commonly prescribed for this indication, and male osteoporosis imparts a substantial burden on both health and society. We compared the risk of osteoporosis and fractures in older men commencing treatment with either dutasteride or finasteride. We hypothesized that, by virtue of more pronounced and widespread 5-alpha reductase inhibition, dutasteride might be associated with a heightened risk of these outcomes.

\section{Methods}

\section{Study design}

We conducted a population-based retrospective cohort study of Ontario men aged 66 years or older with no history of osteoporosis who commenced treatment with dutasteride or finasteride between January 1, 2006 and December 31, 2012. This study was approved by the Research Ethics Board of Sunnybrook Health Sciences Centre, Toronto, Canada.

\section{Data sources}

We used the Ontario Drug Benefit (ODB) database to identify prescription drugs dispensed to Ontario residents aged 65 years or older, excluding the first year of eligibility for drug coverage (age 65) to avoid incomplete records.
We obtained information regarding hospital admissions using the Canadian Institute for Health Information Discharge Abstract Database. We used the Canadian Institute for Health Information National Ambulatory Care Reporting System database to capture information regarding emergency department visits. We used the Ontario Health Insurance Plan database to obtain data regarding services provided by Ontario physicians and the Ontario Cancer Registry to exclude men with a history of prostate cancer. To identify patients with co-morbid illness, we used validated administrative registries to capture diagnoses of diabetes, hypertension, chronic obstructive pulmonary disease, asthma and congestive heart failure [23-27]. We determined physician speciality using the Institute for Clinical Evaluative Sciences Physician Database. Finally, we obtained basic demographic data from the Registered Persons Database. These databases, which are securely linked using unique, encoded identifiers and analyzed at the Institute for Clinical Evaluative Sciences (ICES, www. ices.on.ca). The use of these data sources and study methods are similar to those of our previously published studies exploring drug safety [28-30].

\section{Identification of cohort}

We identified individuals prescribed dutasteride or finasteride using the ODB database, defining the index date as the date of first prescription for either drug. To restrict our analysis to new users of these drugs, we excluded individuals who received a prescription for either drug in the year before the index date. We deemed treatment continuous if a prescription was refilled within 1.5 times the days supplied by the preceding prescription. In both groups, we excluded individuals diagnosed with osteoporosis or a fragility fracture (see codes in Additional file 1 appendix) in the year preceding the index date, as well as those individuals who filled a prescription for oral bisphosphonates during this period. To avoid the potential confounding effects of prostate cancer and its treatments, we excluded men with a history of prostate cancer in the five years preceding the index date. We censored patients who discontinued treatment (defined by the date of the final prescription plus 1.5 times the prescription days' supply), switched between study drugs, after two years of observation, at death, or at the end of follow-up (December 31, 2014), whichever occurred first.

To ensure the similarity of patients prescribed dutasteride and finasteride, we employed a matching algorithm using a high-dimensional propensity score approach to generate propensity scores for all patients in the cohort, as previously described $[29,30]$. Variables forced into the propensity score included age, sex, Charlson comorbidity score, income quintile and long-term care status. We matched each patient treated with dutasteride to one patient treated with finasteride on propensity score (within 0.2 standard deviations), age at index date (within 2 years) and year of cohort entry. 


\section{Outcomes}

The primary outcome was a new diagnosis of osteoporosis, defined as any one of a physician visit, emergency department visit or hospital admission for osteoporosis (see supplemental appendix for International Classification of Diseases [ICD], Ninth and Tenth revision codes), or receipt of a prescription for an oral bisphosphonate. We considered only the first physician visit, hospital admission or emergency department visit for osteoporosis as a study outcome in patients who had multiple such encounters during the study period. In secondary analyses, we compared rates of osteoporotic or fragility fractures (Additional file 1 appendix for ICD-9 and ICD-10 codes). These codes have been previously validated for the diagnosis of osteoporosis in women, with accuracy measures exceeding $90 \%$ for discriminating osteoporosis from normal bone mineral density [31]. To test the specificity of our findings, we examined hospital visits for cataract surgery, since there is no plausible reason why the choice of dutasteride or finasteride would differentially influence this outcome.

\section{Statistical analysis}

We calculated descriptive statistics for patients' baseline demographic and clinical characteristics, and computed standardized differences to test for intergroup differences, with differences $<0.1$ indicating good balance [32]. We conducted a matched Cox proportional hazards regression analysis for each outcome using finasteride as the reference group, given our prespecified hypothesis that dutasteride would be associated with an increased risk of osteoporosis and fractures. We adjusted all models for any baseline characteristics with a standardized difference exceeding 0.1 following propensity score matching. We did not conduct a sample size calculation; our study was population-based and we studied all eligible patients. All analyses were performed using SAS version 9.3 (SAS Institute, Cary, North Carolina).

\section{Results}

During the six-year accrual period, we identified 31,615 individuals treated with dutasteride who were matched to an equal number of subjects treated with finasteride. Patients treated with dutasteride were followed for a median of 328 days (interquartile range 74 to 730 days), while those treated with finasteride were followed for a median of 313 days (interquartile range 64 to 730 days). Collectively, individuals in the cohort contributed a total of 65,804 person-years of follow-up. After propensity score matching, the two groups were highly similar in terms of demographics, medical illnesses and concomitant medications associated with osteoporosis and fractures (Table 1). However, patients differed with respect to the specialty of prescribing physician, with dutasteride-treated individuals more likely to have treatment prescribed by a urologist [16,862 (53.3\%) versus $11,402(36.1 \%)]$, whereas finasteride was more likely to be initiated by family physicians [13,553 (42.9\%) versus 8924 (28.2\%)] (Table 1).

In the primary analysis, osteoporosis was diagnosed in 1569 individuals, with a lower rate observed among men prescribed dutasteride relative to finasteride [2.2 versus 2.6 per 100 person-years; hazard ratio (HR) 0.82, 95\% confidence interval (CI) 0.72 to 0.93]. This difference was no longer statistically significant following adjustment for physician specialty (adjusted HR $0.90,95 \%$ CI 0.78 to 1.02 ) (Table 2). In the secondary analysis, we found no difference in the risk of osteoporotic or fragility fracture between men prescribed dutasteride or finasteride (adjusted HR 1.04, 95\% CI 0.86 to 1.25 ) (Table 2). As expected, we found no difference in cataract surgery between the two groups (HR 0.98 ; $95 \%$ CI 0.89 to 1.09 ).

\section{Discussion}

In this population-based study, we found no difference in the risk of fractures between older men treated with dutasteride or finasteride. Conversely, and in contrast to our study hypothesis, we found a lower incidence of osteoporosis in dutasteride-treated men compared with men treated with finasteride, but this was not statistically significant after adjustment for physician specialty. Our findings do not support a heightened risk of adverse bone outcomes among older men treated with dutasteride relative to finasteride, and that this drug can be used safely in this regard.

The finding that dutasteride did not increase the risk of adverse bone outcomes was unexpected in light of evidence that it inhibits dihydrotestosterone production to a greater extent than finasteride and that men with osteoporosis have lower levels of this androgen than men with normal bone mineral density $[9,15]$. One possible explanation for this discordance is that dutasteridemediated inhibition of osteoblast 5-alpha reductase activity is compensated for by higher levels of intracellular testosterone, which undergoes subsequent aromatization to estradiol $[6,13,33]$. This reasoning is supported by studies in men demonstrating better correlation between bone mineral density and serum estradiol rather than testosterone [33, 34]. Because it does not inhibit 5-alpha reductase in osteoblasts, this phenomenon would not be expected to occur with finasteride.

Another potential explanation for the lower crude rates of osteoporosis among dutasteride-treated men relates to the greater frequency with which this drug was prescribed by urologists relative to finasteride. Despite universal coverage of physician services, Ontario residents with high educational attainment have more contact with specialists and bypass primary care to reach specialists more often than those with lower education [35]. Extending these findings to our study, 
Table 1 Baseline characteristics

\begin{tabular}{|c|c|c|c|}
\hline Variable & $\begin{array}{l}\text { Dutasteride users } \\
(n=31,615)\end{array}$ & $\begin{array}{l}\text { Finasteride users } \\
(n=31,615)\end{array}$ & $\begin{array}{l}\text { Standardized } \\
\text { Difference }\end{array}$ \\
\hline Age (median, IQR) & $75(71-81)$ & $75(71-81)$ & 0.00 \\
\hline $66-74$ & $15,221(48.1 \%)$ & $15,150(47.9 \%)$ & 0.00 \\
\hline $75-84$ & $12,940(40.9 \%)$ & $13,031(41.2 \%)$ & 0.01 \\
\hline $85+$ & $3454(10.9 \%)$ & $3434(10.9 \%)$ & 0.00 \\
\hline \multicolumn{4}{|l|}{ Charlson Co-morbidity Index, No. (\%) (2 years hospitalization data) } \\
\hline No hospitalization & $23,643(74.8 \%)$ & $23,547(74.5 \%)$ & 0.01 \\
\hline 0 & $3365(10.6 \%)$ & $3241(10.3 \%)$ & 0.01 \\
\hline 1 & $1740(5.5 \%)$ & $1785(5.6 \%)$ & 0.01 \\
\hline $2+$ & $2867(9.1 \%)$ & $3042(9.6 \%)$ & 0.02 \\
\hline Number of prescription medications in previous year (median, IQR) & $8(4-11)$ & $8(4-11)$ & 0.00 \\
\hline Residence in a long-term care facility, №. (\%) & $592(1.9 \%)$ & $724(2.3 \%)$ & 0.03 \\
\hline \multicolumn{4}{|l|}{ Medication use in previous 365 days, No. (\%) } \\
\hline Oral corticosteroid & $1562(4.9 \%)$ & $1696(5.4 \%)$ & 0.02 \\
\hline Testosterone & $357(1.1 \%)$ & $265(0.8 \%)$ & 0.03 \\
\hline Tenofovir & $6(0.0 \%)$ & $14(0.0 \%)$ & 0.01 \\
\hline Thyroid hormone & $2452(7.8 \%)$ & $2409(7.6 \%)$ & 0.01 \\
\hline Alpha-adrenergic blocker & $5630(17.8 \%)$ & $6156(19.5 \%)$ & 0.04 \\
\hline Anticonvulsants & $416(1.3 \%)$ & $477(1.5 \%)$ & 0.02 \\
\hline Tricyclic antidepressants & $1167(3.7 \%)$ & $1213(3.8 \%)$ & 0.01 \\
\hline Selective serotonin reuptake inhibitors & $2465(7.8 \%)$ & $2561(8.1 \%)$ & 0.01 \\
\hline Other antidepressants & $13,798(43.6 \%)$ & $13,024(41.2 \%)$ & 0.05 \\
\hline Antipsychotics & $859(2.7 \%)$ & $948(3.0 \%)$ & 0.02 \\
\hline Loop diuretics & $3257(10.3 \%)$ & $3334(10.5 \%)$ & 0.01 \\
\hline Thiazide diuretics & $5930(18.8 \%)$ & $5727(18.1 \%)$ & 0.02 \\
\hline Thiazolidinediones & $628(2.0 \%)$ & $684(2.2 \%)$ & 0.01 \\
\hline Proton pump inhibitors & $8439(26.7 \%)$ & $8386(26.5 \%)$ & 0.00 \\
\hline Benzodiazepines & $5131(16.2 \%)$ & $4987(15.8 \%)$ & 0.01 \\
\hline \multicolumn{4}{|l|}{ Previous diagnoses, №. (\%) } \\
\hline Myocardial infarction & $2325(7.4 \%)$ & $2440(7.7 \%)$ & 0.01 \\
\hline Diabetes & $9531(30.1 \%)$ & $9647(30.5 \%)$ & 0.01 \\
\hline Asthma & $3678(11.6 \%)$ & $3641(11.5 \%)$ & 0.00 \\
\hline Congestive heart failure & $3675(11.6 \%)$ & $3855(12.2 \%)$ & 0.02 \\
\hline Chronic obstructive pulmonary disease & $7717(24.4 \%)$ & 7601 (24.0\%) & 0.01 \\
\hline Dementia & $3445(10.9 \%)$ & $3639(11.5 \%)$ & 0.02 \\
\hline Chronic kidney disease & 1798 (5.7\%) & 1931 (6.1\%) & 0.02 \\
\hline Rheumatoid arthritis & $94(0.3 \%)$ & $117(0.4 \%)$ & 0.01 \\
\hline Systemic lupus erythematosus & $1888(6.0 \%)$ & 1954 (6.2\%) & 0.01 \\
\hline \multicolumn{4}{|l|}{ Medical conditions in previous 2 years, No. (\%) } \\
\hline Alcohol abuse & $327(1.0 \%)$ & $384(1.2 \%)$ & 0.02 \\
\hline Stroke or transient ischemic attack & $545(1.7 \%)$ & $583(1.8 \%)$ & 0.01 \\
\hline \multicolumn{4}{|l|}{ Prescribing physician, No. (\%) } \\
\hline Family physician & $8924(28.2 \%)$ & $13,553(42.9 \%)$ & 0.31 \\
\hline Urologist & $16,862(53.3 \%)$ & $11,402(36.1 \%)$ & 0.35 \\
\hline
\end{tabular}


Table 1 Baseline characteristics (Continued)

\begin{tabular}{|c|c|c|c|}
\hline Variable & $\begin{array}{l}\text { Dutasteride users } \\
(n=31,615)\end{array}$ & $\begin{array}{l}\text { Finasteride users } \\
(n=31,615)\end{array}$ & $\begin{array}{l}\text { Standardized } \\
\text { Difference }\end{array}$ \\
\hline Other & $1106(3.5 \%)$ & $1543(4.9 \%)$ & 0.07 \\
\hline Unknown & $4723(14.9 \%)$ & $5117(16.2 \%)$ & 0.03 \\
\hline \multicolumn{4}{|c|}{ Specialist in preceding year, No. (\%) } \\
\hline Nephrologist & $2249(7.1 \%)$ & $2484(7.9 \%)$ & 0.03 \\
\hline Endocrinologist & $1973(6.2 \%)$ & $1615(5.1 \%)$ & 0.05 \\
\hline Geriatrician & $1191(3.8 \%)$ & $1389(4.4 \%)$ & 0.03 \\
\hline \multicolumn{4}{|c|}{ Income Quintile, No. (\%) } \\
\hline 1 (lowest) & $5273(16.7 \%)$ & $5265(16.7 \%)$ & 0.00 \\
\hline 2 & $6123(19.4 \%)$ & $6183(19.6 \%)$ & 0.00 \\
\hline 3 & $6178(19.5 \%)$ & $6245(19.8 \%)$ & 0.01 \\
\hline 4 & $6711(21.2 \%)$ & $6746(21.3 \%)$ & 0.00 \\
\hline 5 (highest) & $7217(22.8 \%)$ & $7062(22.3 \%)$ & 0.01 \\
\hline Missing & $113(0.4 \%)$ & $114(0.4 \%)$ & 0.00 \\
\hline
\end{tabular}

it is possible that the lower incidence of osteoporosis among dutasteride recipients reflects in part greater knowledge about osteoporosis prevention and a healthy user effect, an assertion supported by the loss of a statistically significant association between dutasteride and osteoporosis after adjustment for physician specialty. Detection bias may also account for this finding because osteoporosis screening is more likely to be undertaken by family physicians than urologists, with the former ordering approximately $80 \%$ of bone mineral density tests in Ontario [36]. Importantly, however, rates of osteoporosis screening among men at high risk for the disease consistently lag far below those of women. In Ontario, age-standardized rates of bone mineral density testing within 6 months of a fracture were 8 per 100 men, compared with 16.1 per 100 women, in 2009/2010 [37]. Similarly, only $11 \%$ of Ontario men between the ages of 68 to 70 who had never previously undergone bone mineral testing received such a test in 2009/2010, compared with over $40 \%$ of Ontario women in this same high-risk group
[37]. These findings are supported by those of a Canadian cohort study in which $90 \%$ of men with fragility fractures remained undiagnosed and untreated for osteoporosis despite participation in a five-year study with the potential to raise awareness of the disease among participants and their physicians [38]. Interventions to promote osteoporosis diagnosis and treatment among men are warranted.

Our study builds on previous observational studies examining the association between adverse bone outcomes and 5-alpha reductase inhibitors in several ways. First, ours is the first study to specifically compare the risk of osteoporosis and fractures between dutasteride and finasteride. Previous studies have risk estimates for 5-alpha reductase inhibitor exposure relative to a control group of untreated men [18-22]. Second, we generated additional data regarding the risk of osteoporosis in men treated with 5 -alpha reductase inhibitors, an outcome examined in only one case control study with 47 osteoporosis patients exposed to one of these drugs [21]. Finally, we were able

Table 2 Risk of osteoporosis and fractures among patients treated with dutasteride or finasteride

\begin{tabular}{|c|c|c|c|c|c|c|}
\hline & $\begin{array}{l}\text { Number }(\%) \text { of events } \\
\text { in dutasteride treated } \\
\text { individuals }(n=31,615)\end{array}$ & $\begin{array}{l}\text { Number (\%) of events } \\
\text { in finasteride treated } \\
\text { individuals }(n=31,615)\end{array}$ & $\begin{array}{l}\text { Rate in dutasteride } \\
\text { treated individuals } \\
\text { (per } 100 \text { person years) }\end{array}$ & $\begin{array}{l}\text { Rate in finasteride } \\
\text { treated individuals } \\
\text { (per } 100 \text { person years) }\end{array}$ & $\begin{array}{l}\text { Unadjusted } \\
\text { hazard ratio } \\
(95 \% \text { confidence } \\
\text { intervall) }\end{array}$ & $\begin{array}{l}\text { Adjusted } \\
\text { hazard ratio } \\
(95 \% \text { confidence } \\
\text { interval) }^{\mathrm{a}}\end{array}$ \\
\hline \multicolumn{7}{|l|}{ Main outcomes } \\
\hline Osteoporosis & 729 (2.3\%) & $840(2.7 \%)$ & 2.2 & 2.6 & $\begin{array}{l}0.82 \\
(0.72 \text { to } 0.93)\end{array}$ & $\begin{array}{l}0.90 \\
(0.78 \text { to } 1.02)\end{array}$ \\
\hline Fracture & $437(1.4 \%)$ & $463(1.5 \%)$ & 1.3 & 1.4 & $\begin{array}{l}1.01 \\
\text { (0.85 to } 1.21)\end{array}$ & $\begin{array}{l}1.04 \\
\text { (0.86 to } 1.25)\end{array}$ \\
\hline \multicolumn{7}{|l|}{ Tracer Outcome } \\
\hline $\begin{array}{l}\text { Cataract } \\
\text { surgery }\end{array}$ & 1487 (4.7\%) & 1551 (4.9\%) & 4.6 & 4.8 & $\begin{array}{l}0.99 \\
(0.90 \text { to } 1.08)\end{array}$ & $\begin{array}{l}0.98 \\
(0.89 \text { to } 1.09)\end{array}$ \\
\hline
\end{tabular}

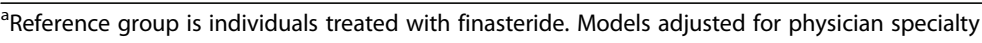


to demonstrate the important confounding role of physician specialty in the association between adverse bone outcomes and 5-alpha reductase inhibitors. Specifically, the finding that adjustment for physician specialty reversed the association between dutasteride and osteoporosis suggests that future studies of these drugs consider accounting for health service delivery and other indicators of a potential healthy user effect.

Our study has some limitations. We used administrative data rather than measurement of bone mineral density to identify patients with osteoporosis, and codes used for ascertaining osteoporosis have not been validated among older men. We had no access to relevant clinical variables such as smoking history, alcohol use, body mass index and use of over the counter calcium and vitamin D supplementation. However, these limitations apply equally to both groups of patients. We followed patients for two years from the time of drug initiation; it is possible that additional outcomes may have been observed with longer follow-up. We selected a two-year follow-up because of the advanced age of our cohort, reasoning that prostate cancer and frailty could emerge as important confounders with a longer follow-up period. In addition, we had no information regarding medication adherence. Finally, because we conducted our analyses in men aged 66 years and over with no prior history of osteoporosis or fractures, our findings may not be applicable to younger patients and those with pre-existing bone disease.

\section{Conclusions}

We found no difference in the incidence of a new diagnosis of osteoporosis among older men treated with either dutasteride or finasteride. Similarly, we found no differential risk of fractures with dutasteride. These findings provide a measure of reassurance that widespread inhibition of 5-alpha-reductase does not negatively affect bone health in older men, and that dutasteride can be safely used in this regard.

\section{Additional file}

Additional files 1: Online Appendix ICD-9 and ICD-10 Codes For Outcome Ascertainment. Administrative codes for osteoporosis and fractures. (DOCX $13 \mathrm{~kb})$

\section{Abbreviations}

Cl: Confidence interval; HR: Hazard ratio; ICD: International Classification of Diseases; ICES: Institute for Clinical Evaluative Sciences; ODB: Ontario Drug Benefit

\section{Acknowledgements}

We thank Brogan Inc., Ottawa for use of their Drug Product and Therapeutic Class Database. Parts of this material are based on data and information compiled and provided by the Canadian Institute for Health Information. However, the analyses, conclusions, opinions and statements expressed herein are those of the author, and not necessarily those of Canadian Institute for Health Information.

\section{Funding}

Tony Antoniou is supported by a new investigator award from the Canadian Institutes of Health Research and Clinician Investigator Award from the University of Toronto Department of Family and Community Medicine. This project was supported by research funds from Canadian Drug Safety and Effectiveness Research Network and by the Institute for Clinical Evaluative Sciences, which is funded by a grant from the Ontario Ministry of Health and Long-Term Care. The Canadian Drug Safety and Effectiveness Research Network is funded by an Emerging Team Grant from the Canadian Institutes of Health Research (grant no. ETG-92247). The sponsors had no role in the design and conduct of the study; in the collection, analysis, and interpretation of the data; or in the preparation, review, or approval of the manuscript. The opinions, results and conclusions reported in this paper are those of the authors and are independent from the funding sources. No endorsement by the Institute for Clinical Evaluative Sciences or the Ontario Ministry of Health and Long-Term Care is intended or should be inferred.

\section{Availability of data and materials}

The dataset from this study is held securely in coded form at the Institute for Clinical Evaluative Sciences (ICES). While data sharing agreements prohibit ICES from making the dataset publicly available, access may be granted to those who meet pre-specified criteria for confidential access, available at www.ices.on.ca/DAS. The full dataset creation plan and underlying analytic code are available from the authors upon request, understanding that the programs may rely upon coding templates or macros that are unique to ICES.

\section{Authors' contributions}

$T A, E M, Z Y, T G, M T$, JMWH, MMM and DNJ contributed substantially to the study design, data analysis and interpretation of the data. TA drafted the manuscript. $E M, Z Y, T G, M T, J M W H, M M M$ and DNJ critically revised the manuscript. All authors approved the final version of the manuscript submitted for publication.

\section{Ethics approval and consent to participate}

ICES is a prescribed entity under section 45 of Ontario's Personal Health Information Protection Act. Section 45 authorizes ICES to collect personal health information, without consent, for the purpose of analysis or compiling statistical information with respect to the management of, evaluation or monitoring of, the allocation of resources to or planning for all or part of the health system. Projects conducted under section 45 , by definition, do not require review by a Research Ethics Board. This project was conducted under section 45, and approved by ICES' Privacy and Compliance Office. Ethics approval was obtained from the Research Ethics Board of Sunnybrook Health Sciences Centre, Toronto, Ontario, Canada. This study is based on the analysis of administrative health care data and, as such, patient consent was not required.

\section{Competing interests}

Tony Antoniou has no conflicts of interest. Erin MacDonald has no conflicts of interest. Zhan Yao has no conflicts of interest. Tara Gomes has no conflicts of interest. Mina Tadrous has no conflicts of interest. Joanne M-W Ho has no conflicts of interest. During the past three years, Muhammad M. Mamdani has served on advisory boards and/or received honoraria from Astra Zeneca, Bristol-Myers Squibb, Eli Lilly and Company, Glaxo Smith Kline, Hoffman La Roche, Novartis, Novo Nordisk and Pfizer. David N. Juurlink has no conflicts of interest.

\section{Publisher's Note}

Springer Nature remains neutral with regard to jurisdictional claims in published maps and institutional affiliations.

\section{Author details}

'Department of Family and Community Medicine, St. Michael's Hospital, 410 Sherbourne Street, 4th Floor, Toronto, ON M4X 1K2, Canada. ${ }^{2}$ Li Ka Shing Knowledge Institute, St. Michael's Hospital, 410 Sherbourne Street, 4th Floor, Toronto, ON M4X 1K2, Canada. ${ }^{3}$ University of Toronto, 410 Sherbourne Street, 4th Floor, Toronto, ON M4X 1 K2, Canada. ${ }^{4}$ Institute for Clinical Evaluative Sciences, 410 Sherbourne Street, 4th Floor, Toronto, ON M4X 1K2, Canada. ${ }^{5}$ Applied Health Research Centre, St. Michael's Hospital, Toronto, ON, Canada. ${ }^{6}$ Department of Medicine, McMaster University, Hamilton, ON, Canada. ${ }^{7}$ Schlegel Research Institute for Aging, Waterloo, ON, Canada. ${ }^{8}$ King Saud University, Riyadh, Saudi Arabia. ${ }^{9}$ Sunnybrook Research Institute, Toronto, ON, Canada. 
Received: 9 November 2017 Accepted: 7 May 2018

Published online: 22 May 2018

\section{References}

1. Ebeling PR. Clinical practice. Osteoporosis in men. N Engl J Med. 2008;358: 1474-82.

2. Tarride JE, Guo N, Hopkins R, Leslie WD, Morin S, Adachi JD, et al. The burden of illness of osteoporosis in Canadian men. J Bone Miner Res. 2012; 27(8):1830-8.

3. Jiang HX, Majumdar SR, Dick DA, Moreau M, Raso J, Otto DD, et al. Development and initial validation of a risk score for predicting in-hospital and 1-year mortality in patients with hip fractures. J Bone Miner Res. 2005; 20:494-500.

4. Jackson JA, Riggs MW, Spiekerman AM. Testosterone deficiency as a risk factor for hip fractures in men: a case-control study. Am J Med Sci. 1992; 304:4-8.

5. Behre HM, Kliesch S, Leifke E, Link TM, Nieschlag E. Long-term effect of testosterone therapy on bone mineral density in hypogonadal men. J Clin Endocrinol Metab. 1997:82:2386-90

6. Mohamad NV, Soelaiman IN, Chin KY. A concise review of testosterone and bone health. Clin Interv Aging. 2016;11:1317-24.

7. Gori F, Hofbauer LC, Conover CA, Khosla S. Effects of androgens on the insulin-like growth factor system in an androgen-responsive human osteoblastic cell line. Endocrinology. 1999;140:5579-86.

8. Kasperk C, Fitzsimmons R, Strong D, Mohan S, Jennings J, Wergedal J, et al. Studies of the mechanism by which androgens enhance mitogenesis and differentiation in bone cells. J Clin Endocrinol Metab. 1990;71:1322-9.

9. Ilangovan R, Sittadjody S, Balaganesh M, Sivakumar R, Ravi Sankar B, et al. Dihydrotestosterone is a determinant of calcaneal bone mineral density in men. J Steroid Biochem Mol Biol. 2009:117:132-8.

10. Saartok T, Dahlberg E, Gustafsson JA. Relative binding affinity of anabolicandrogenic steroids: comparison of the binding to the androgen receptors in skeletal muscle and in prostate, as well as to sex hormone-binding globulin. Endocrinology. 1984;114:2100-6.

11. Bartsch G, Rittmaster RS, Klocker $\mathrm{H}$. Dihydrotestosterone and the concept of 5alpha-reductase inhibition in human benign prostatic hyperplasia. Eur Urol. 2000;37:367-80

12. Nickel JC, Méndez-Probst CE, Whelan TF, Paterson RF, Razvi H. 2010 update: guidelines for the management of benign prostatic hyperplasia. Can Urol Assoc J. 2010;4:310-6.

13. Issa S, Schnabel D, Feix M, Wolf L, Schaefer HE, Russell DW, et al. Human osteoblast-like cells express predominantly steroid 5alpha-reductase type 1. J Clin Endocrinol Metab. 2002:87:5401-7.

14. Amory JK, Wang C, Swerdloff RS, Anawalt BD, Matsumoto AM, Bremner WJ, et al. The effect of 5alpha-reductase inhibition with dutasteride and finasteride on semen parameters and serum hormones in healthy men. J Clin Endocrinol Metab. 2007;92:1659-65

15. Clark RV, Hermann DJ, Cunningham GR, Wilson TH, Morrill BB, Hobbs S. Marked suppression of dihydrotestosterone in men with benign prostatic hyperplasia by dutasteride, a dual 5-alpha-reductase inhibitor. J Clin Endocrinol Metab. 2004;89:2179-84

16. Amory JK, Anawalt BD, Matsumoto AM, Page ST, Bremner WJ, Wang C, et al. The effect of 5alpha-reductase inhibition with dutasteride and finasteride on bone mineral density, serum lipoproteins, hemoglobin, prostate specific antigen and sexual function in healthy young men. J Urol. 2008;179:2333-8.

17. Mačukat IR, Spanjol J, Orlič ZC, Butorac MZ, Marinovič M, Ćupič DF. The effect of 5alpha-reductase inhibition with finasteride and dutasteride on bone mineral density in older men with benign prostatic hyperplasia. Coll Antropol. 2014;38:835-9

18. Robinson D, Garmo H, Stattin P, Michaëlsson K. Risk of fractures and falls during and after 5-a Reductase inhibitor use: a Nationwide cohort study. PLoS One. 2015;10(10):e0140598.

19. Vestergaard P, Rejnmark L, Mosekilde L. Risk of fractures associated with treatment for benign prostate hyperplasia in men. Osteoporos Int. 2011;22: 731-7.

20. Souverein PC, Van Staa TP, Egberts AC, De la Rosette JJ, Cooper C, Leufkens HG. Use of alpha-blockers and the risk of hip/femur fractures. J Intern Med. 2003;254:548-54

21. Lin $\mathrm{WL}$, Hsieh $\mathrm{YW}$, Lin $\mathrm{CL}$, Sung FC, Wu CH, Kao CH. A population-based nested case-control study: the use of 5-alpha-reductase inhibitors and the increased risk of osteoporosis diagnosis in patients with benign prostate hyperplasia. Clin Endocrinol. 2015;82:503-8.

22. Jacobsen SJ, Cheetham TC, Haque R, Shi JM, Loo RK. Association between 5-alpha reductase inhibition and risk of hip fracture. JAMA. 2008:300:1660-4

23. Hux JE, Ivis F, Flintoft V, Bica A. Diabetes in Ontario: determination of prevalence and incidence using a validated administrative data algorithm. Diabetes Care. 2002;25:512-6.

24. Tu K, Campbell NR, Chen ZL, Cauch-Dudek KJ, McAlister FA. Accuracy of administrative databases in identifying patients with hypertension. Open Med. 2007;1:e18-26.

25. Gershon AS, Wang C, Guan J, Vasilevska-Ristovska J, Cicutto L, To T. Identifying individuals with physcian diagnosed COPD in health administrative databases. COPD. 2009:6:388-94.

26. Gershon AS, Wang C, Guan J, Vasilevska-Ristovska J, Cicutto L, To T. Identifying patients with physician-diagnosed asthma in health administrative databases. Can Respir J. 2009;16:183-8.

27. Schultz SE, Rothwell DM, Chen Z, Tu K. Identifying cases of congestive heart failure from administrative data: a validation study using primary care patient records. Chronic Dis Inj Can. 2013;33:160-6.

28. Antoniou T, Macdonald EM, Yao Z, Hollands S, Gomes T, Tadrous M, et al. Association between statin use and ischemic stroke or major hemorrhage in patients taking dabigatran for atrial fibrillation. CMAJ. 2017:189:E4-E10.

29. Juurlink DN, Gomes T, Shah BR, Mamdani MM. Adverse cardiovascular events during treatment with glyburide (glibenclamide) or gliclazide in a high-risk population. Diabet Med. 2012;29:1524-8.

30. Antoniou T, Yao Z, Camacho X, Mamdani MM, Juurlink DN, Gomes T. Safety of valproic acid in patients with chronic obstructive pulmonary disease: a population-based cohort study. Pharmacoepidemiol Drug Saf. 2015;24:256-61.

31. Leslie WD, Lix LM, Yogendran MS. Validation of a case definition for osteoporosis disease surveillance. Osteoporos Int. 2011;2:37-46.

32. Austin PC, Grootendorst P, Anderson GM. A comparison of the ability of different propensity score models to balance measured variables between treated and untreated subjects: a Monte Carlo study. Stat Med. 2007:26:734-53.

33. Van Pottelbergh I, Goemaere S, Kaufman JM. Bioavailable estradiol and an aromatase gene polymorphism are determinants of bone mineral density changes in men over 70 years of age. J Clin Endocrinol Metab. 2003;88: 3075-81.

34. Gennari L, Merlotti D, Martini G, Gonnelli S, Franci B, Campagna S, et al. Longitudinal association between sex hormone levels, bone loss, and bone turnover in elderly men. J Clin Endocrinol Metab. 2003;88:5327-33.

35. Glazier RH, Agha MM, Moineddin R, Sibley LM. Universal health insurance and equity in primary care and specialist office visits: a population-based study. Ann Fam Med. 2009;7:396-405.

36. Health Quality Ontario. Utilization of DXA bone mineral densitometry in Ontario: an evidence-based analysis. Ont Health Technol Assess Ser. 2006;6: $1-180$.

37. Jaglal S, Hawker G, Croxford R, Cameron C, Schott AM, Munce S, et al. Impact of a change in physician reimbursement on bone mineral density testing in Ontario, Canada: a population-based study. CMAJ Open. 2014;2:E45-50.

38. Papaioannou A, Kennedy CC, loannidis G, Gao Y, Sawka AM, Goltzman D, et al. The osteoporosis care gap in men with fragility fractures: the Canadian multicentre osteoporosis study. Osteoporos Int. 2008;19:581-7.

Ready to submit your research? Choose BMC and benefit from

- fast, convenient online submission

- thorough peer review by experienced researchers in your field

- rapid publication on acceptance

- support for research data, including large and complex data types

- gold Open Access which fosters wider collaboration and increased citations

- maximum visibility for your research: over $100 \mathrm{M}$ website views per year

At BMC, research is always in progress.

Learn more biomedcentral.com/submissions 